\title{
COMENTÁRIOS SOBRE A REPRESENTAÇÃO DA ARQUITETURA EM IMAGENS E OBJETOS, O COSTUME DA OFERENDA ARQUITETÔNICA E A ICONOGRAFIA DO PORTADOR DO MODELO
}

\author{
Artur Rozestraten - Doutorando FAU/USP, Bolsista FAPESP
}

Essa comunicação trata da representação da arquitetura em imagens e objetos, do costume da oferenda arquitetônica e da iconografia do portador do modelo arquitetônico.

Tomando como base a figura portando o modelo de arquitetura na arte bizantina, interessa a essa pesquisa investigar suas relações com o imaginário em torno da criação artística e do projeto arquitetônico.

A iconografia em foco passeia entre o oriente próximo e o ocidente com idas e vindas; dos mosaicos da Itália para os relevos da Armênia; dos afrescos balcânicos para a escultura gótica da Europa ocidental.

As considerações que serão feitas aqui são parte da pesquisa de doutorado que desenvolvo junto Departamento de História da Arquitetura e Estética do projeto da Faculdade de Arquitetura e Urbanismo da Universidade de São Paulo, sob a orientação do Prof. Dr. Luiz Munari, e que conta com o apoio da FAPESP.

Para tanto é interessante tentar compor uma genealogia da imagem, suas raízes e sua memória.

No sexto milênio, no sudeste europeu, objetos com formas arquitetônicas eram enterrados junto às fundações dos templos, tudo indica que com a função de banopfer - oferenda de construção.

Escavações arqueológicas no santuário da deusa Hera, na ilha de Samos, trouxeram à luz dezenas de pequenos templos cerâmicos, miniaturas, caracterizadas como modelos arquitetônicos, que provavelmente foram ali deixados como oferendas.

O relevo assírio de Khorsabad, datado no século VIII a.C., mostra um cortejo de tributários, no qual um deles leva nas mãos uma arquitetura em miniatura de uma fortificação com torres.

Esses três exemplos revelam vertentes artísticas e culturais que associam modelos arquitetônicos ao costume da oferenda e do tributo, e que terão grande repercussão no mundo cristianizado.

Nessa relação entre representações reduzidas da arquitetura e o gesto do portador tem origens uma iconografia em relevo, anterior ao mundo cristão, que tem expressões no mundo helenístico com o relevo 
funerário de Cyzique (séc. II a.C.), e o relevo numismático da deusa Tyché (séc. III).

Em meados do séc. VI, o mosaico do bispo Eclesius portando o modelo da igreja em S.Vitale, Ravena inaugura uma representação iconográfica bizantina do motivo artístico do portador do modelo.

$\mathrm{O}$ antigo costume, presente no ocidente e no oriente em torno da bacia do Mediterrâneo, conforma então um tipo, um motivo artístico cristão bem característico, que permeará toda a arte medieval com expressões em mosaico, afresco e relevo.

A originalidade da imagem inaugural do portador do modelo está:

- em sua caracterização inequívoca como arte cristã, integrada à teologia e com posição privilegiada no programa iconográfico das igrejas;

- na relação de semelhança entre a imagem da arquitetura representada no modelo, e as formas da arquitetura real na qual a imagem se insere;

- na técnica artística do mosaico, eminentemente bidimensional, e distinto das imagens em relevo até então conhecidas;

- no registro histórico claro e intencional da identidade do portador do modelo, pelo nome escrito junto à figura.

$\mathrm{Na}$ história da iconografia cristã, os portadores do modelo de arquitetura - como Eclesius - são, ao lado dos mártires, as primeiras figuras históricas a ingressarem em um universo de imagens até então exclusivo de personagens do antigo e do novo testamento. Esta participação do indivíduo real, retratado, no universo mítico cristão, inaugura uma nova significação política da iconografia em foco. Significação política, logo pública, que se apropria, e subverte, a antiga tradição de retratos funerários acrescentam agora a novidade da imagem dos vivos.

$O$ alcance político deste retrato de Eclesius na posição privilegiadíssima de portador do modelo arquitetônico teve grande repercussão. E instigou o desejo de futuros pretendentes a esse papel. A tal ponto que papas, reis, príncipes e senhores construíram igrejas onde se fizeram retratar - muitas vezes ainda em vida - portando o modelo de arquitetura.

Formou-se desde então um vínculo histórico entre a imagem do portador do modelo, e a afirmação e legitimação do poder do cristianismo na Europa, e no Oriente próximo durante a Idade Média.

Se no mundo antigo o costume do tributo e da oferenda deixou objetos e imagens como vestígio arqueológico, no mundo medieval a imagem da figura portando o modelo de arquitetura não possui uma 
correspondência tão óbvia com modelos miniaturizados da arquitetura, como se poderia supor, por exemplo: oratórios, relicários, sacrários ou maquetes de arquitetos.

A imagem parece estabelecer uma relação direta com a arquitetura real da igreja, sem intermediações. Mas, a possibilidade de relacionar o modelo representado na imagem a um objeto real, traz à tona a questão das maquetes medievais, assunto controverso e de difícil prospecção, já que as evidências materiais e textuais são mínimas.

O que intriga neste assunto é a lacuna entre as evidências da utilização de maquetes pelos arquitetos do Império Romano, e seu retorno na Renascença Italiana.

Afinal há evidências arqueológicas do uso da modelagem tridimensional entre os arquitetos romanos - como a maquete de Niha (séc. II), encontrada junto a um templo próximo à Balbek no Líbano - assim como há também evidências textuais, em Vitrúvio, no seu De Architectura do séc. I a.C., que reforçam essa noção. E na Renascença há diversos exemplos de maquetes de arquiteto.

Mas o que teria havido entre estes dois momentos? Caberia aqui o argumento a silentio de que os arquitetos medievais teriam utilizado maquetes feitas com materiais perecíveis que não deixaram vestígios arqueológicos?

A imagem do arquiteto francês Hugues Libergier portando o modelo de arquitetura no relevo de sua lápide, do século XIII, só aumenta a polêmica em torno da questão. Seria essa imagem uma maquete, ou a imagem de um modelo transcendente, um paradeigma da igreja?

Esse baixo-relevo tem um significado especial dentro da história da iconografia do portador do modelo. Afinal, durante 700 anos o modelo este nas mãos dos representantes da igreja - papas, bispos e santos - ou nas mãos dos detentores do poder político e militar: reis, príncipes e senhores. E só em 1267, aproximadamente, que o modelo chega às mãos do arquiteto.

A autorictas de portador do modelo confere a Hugues Libergier como representante dos arquitetos das catedrais - o reconhecimento social de seu papel como construtor competente do projeto revelado pela inteligência divina.

A imagem não põe em questão a idéia de que o autor de todos os projeto é Deus. E é Deus quem escolhe seus interlocutores e comunica o projeto prefigurado por meio de sonhos ou visões. A participação divina ainda é indispensável no processo de criação arquitetônica, e mesmo na 
garantia de sua materialização. A necessidade desse acordo entre a divindade e o sucesso do empreendimento arquitetônico, como visto, está enraizada profundamente na cultura ocidental, e tem como antagonista o mito bíblico da sabotagem divina ao projeto da torre de Babel.

É certo que Libergier não se coloca como autor do projeto. Preserva-se portanto a idéia da criação arquitetônica como desígnio divino intermediado pelo contratante, em geral um religioso. Mas a imagem é um documento do reconhecimento social da competência técnica do arquiteto para assumir o papel de "construtor de igrejas", isto é, o responsável pela edificação da casa do Senhor e conseqüentemente da igreja como instituição. Responsabilidade post morten eterna, pois o modelo na lápide prestará contas da fidelidade do arquiteto ao projeto divino é será a chave para o reino dos céus.

A partir desse entalhe de Hugues Libergier, o arquiteto com seus instrumentos, seus modelos e seus conhecimentos posiciona-se como a mais nítida expressão da capacidade transformadora da razão humana: aquele que transfere para a realidade sensível o logos divino como expressão artística em pedra, vitrais, vazios e luz. A arte e a técnica desse mestre - a arquitetura - assume o caráter metafórico de uma cosmogonia: é uma arte inaugural, constitutiva, organizadora, que modifica as formas da matéria, do tempo e do espaço transformando a matéria bruta em beleza.

Seria esse reconhecimento social da posição do arquiteto na França gótica uma pré-renascença do caráter vitruviano da arquitetura?

Não seria a própria permanência da arquitetura medieval até os dias de hoje, e a sofisticação das soluções estruturais existentes nestas arquiteturas, um atestado da sobrevivência do caráter tecnológico do projeto arquitetônico na Idade Média?

A imagem do arquiteto com seus instrumentos de medida constituiria, então, uma alegoria tão forte do logos criador que, quase simultaneamente, se desdobraria na iconografia de Deus arquiteto, e geraria imagens como a aplicada na folha de rosto de um manuscrito francês da Bíblia de meados do séc. XIII, em uma de suas primeiras expressões.

Por outro lado a imagem do portador do modelo, nesse mesmo momento histórico se desdobra na iconografia de santos, com S.Gregório e S.Bárbara, e a imagem da arquitetura torna-se emblema ou atributo.

As alterações graduais no entendimento da criação arquitetônica, que ocorreriam desde então, conduziriam a uma outra imagem pintada por Domenico Cresti de Passignano em 1619. 
Nessa tela, o pintor compõe uma cena que mostra Michelangelo apresentando a maquete de S.Pedro ao Papa. A maquete, parcialmente encoberta pelas pessoas, está no chão e sua base se confunde com o piso. Ela é grande e aparentemente pesada para que alguém a segure nas mãos.

Michelangelo está na frente do Papa, e indica a maquete. O Papa num segundo plano, parcialmente encoberto por Michelangelo, também aponta para a maquete como quem questiona, num diálogo.

A mão do arquiteto é conhecida. Passignano pinta em Michelangelo a mão que designa, a mão do criador eternizada na Capela Sixtina pelo próprio artista.

O gesto divino de criação, apropriado pelo arquiteto, torna-se metáfora de um humanismo que assume sua própria criação, metáfora de um mundo construído pelo homem à sua própria imagem e semelhança, e a materialidade mais densa deste mundo criado pelo homem é a arquitetura, edifícios e cidades.

O projeto humanizado, que a iconografia medieval do portador do modelo permite apreender é um percurso do pensamento humano, que se desprende da necessidade da transcendência como logos criador, e toma em suas mãos a construção de sua própria história.

A teoria do dom substitui, desde o séc. XIII, a teoria da iluminação divina na concepção do projeto. Se antes o projeto era concebido no logos divino e revelado misticamente, em sonhos ou visões, entendia-se agora que Deus havia concedido ao homem a capacidade para criar.

Conforme Vasari (1511-1574), o próprio Brunelleschi, ao ser convidado para assumir a obra do Duomo de Florença teria comentado que por se tratar de um templo consagrado a Deus, esse incutiria força, sabedoria e engenho em quem a assumisse ${ }^{1}$. Esse comentário sobre Brunelleschi - que é o arquiteto renascentista por excelência - ainda atribui à divindade participação fundamental na concepção arquitetônica, mas trata como autor o arquiteto. E aqui há uma mudança significativa.

O projeto divino agora é o logos humano, a engenhosidade, a genialidade. E a obra de Vasari ecoa essa filosofia do gênio, primeiro com Brunelleschi e depois com o próprio Michelangelo.

\footnotetext{
1 "Ma ricordandomi che questo è tempio sacrato a Dio, mi confido che, faccendosi in memoria sua, non mancherà di infondere il sapere dov'e' non sia, et agiugnere le forze e la sapienza e l'ingegno a chi sarà autore di tal cosa." Vasari, VoL.III, p.154-155 Edição Torrentiana, 1550.

$<$ http://biblio.signum.sns.it/vasari/consultazione/Vasari/indice.html>
} 
A questão teológica parece encontrar repouso, afinal, a própria capacidade e liberdade do pensamento humano de pensar-se criador da própria idéia da divindade seria um dom cedido pela graça de Deus.

Se no mundo antigo e medieval, parecia haver uma passagem mágica entre a revelação mística do projeto e o fazer construtivo imbrincado nos mistérios da natureza, as reflexões de Leon Battista Alberti fizeram dessa passagem o lugar da prudência, da previsão, da representação científica substituindo a prefiguração divina. $\mathrm{E}$ as imagens emergiram no projeto renascentista com cadernos de anotações, desenhos em perspectiva, maquetes e modelos tridimensionais que gestam o projeto antes da obra. A prefiguração não é mais transcendente, é material e integra pensamento e modelos em um processo que tem um objetivo construtivo.

Mas de que maneira essa laicização crescente do entendimento do processo criativo que caracteriza a própria modernidade repercute no mundo contemporâneo?

$\mathrm{Na}$ procissão do Círio de Nazaré, em homenagem a Nossa Senhora de Nazaré - divindade feminina como Hera e Tyché - os portadores do modelo arquitetônico ressurgem, provocativamente, no mundo contemporâneo.

Tanto os que levam o modelo como ex-voto em ação de graças pela casa construída, quanto os que o levam como oferenda - pedindo auxílio para construir -, colocam-se como parceiros da transcendência, e reafirmam a necessidade de vínculos para além da materialidade da obra.

As origens arcaicas do vínculo entre arquitetura e divindade afloram então, na cidade de Belém do Pará em pleno século XXI, com essas pessoas que se colocam na posição de portadores do modelo. Esses são os interlocutores divinos e, muitas vezes, acumulam funções sendo ao mesmo tempo: arquitetos, contratantes, financiadores da obra e pedreiros.

$\mathrm{Na}$ periferia de Belém, essas pequenas casas - como oratórios atestam materialmente a onipresença divina, e a capacidade humana de superação. Ali, moram juntos, as pessoas e os santos, as crianças, o Cristo e a Virgem. A poética desse mundo sacralizado, com suas arquitetura consagradas parece se sobrepor ao projeto humanista moderno. Ali a antitorre de Babel se materializa em arquiteturas imaginadas e construídas sem arquiteto.

Nesse contexto, um trama de ambigüidades emerge e provoca questões: 
Não seria justamente por essa ausência do arquiteto - como ausência de um lastro tecnológico, de um vínculo com o projeto humanista - que a presença divina ainda se faz indispensável?

Mas, no centro da própria engrenagem da teologia cristã não estariam esses portadores do modelo perpetuando também um certo humanismo, como valorização do fazer humano?

E esse humanismo, que se revela como fatura, não abre uma brecha na teologia para o entendimento do mundo como construção humana e, portanto para o entendimento da própria idéia de divindade como invenção humana?

Em que medida esta iconografia não tem sua força exatamente nesse paradoxo que carrega, como imagem de submissão ao sagrado, ao mesmo tempo em que imagem vaidosa de afirmação pessoal?

\section{Referência Bibliográficas}

ALBERTI, L.B. De Re Aedificatoria. Madrid: Akal, 1991.

POLIÃO, M. V. Da Arquitetura. Tradução de Marco Aurélio Lagonegro. São Paulo: Hucitec, Fupam, 1999.

VASARI, G. Vite de' più eccellenti architetti, pittori, et scultori italiani, da Cimabue insino a' tempi nostri, VoL.III, p.154-155 Edição Torrentiana, 1550.

<http://biblio.signum.sns.it/vasari/consultazione/Vasari/indice.html> 